\title{
A desmoplastic fibroblastoma that developed in the anterior mediastinum: a case report
}

\author{
Tai Hato ${ }^{1 *} \mathbb{D}$, Hiroaki Kashimada ${ }^{1}$, Masatoshi Yamaguchi ${ }^{1}$, Ato Sugiyama ${ }^{1}$, Yoshiaki Inoue ${ }^{1}$, Kohei Aoki ${ }^{1}$, \\ Hiroki Fukuda', Masatoshi Gika', Jun Kikuchi², Takashi Fujino ${ }^{3}$, Takehiko Yamaguchi ${ }^{4}$, Jun-ichi Tamaru², \\ Mitsutomo Kohno ${ }^{1}$ and Mitsuo Nakayama ${ }^{1}$
}

\begin{abstract}
Background: Desmoplastic fibroblastoma (also known as collagenous fibroma) is a benign, slowly growing softtissue tumor. Most desmoplastic fibroblastomas develop in the limbs, neck, or trunk. A mediastinal origin is quite rare.

Case presentation: A 32-year-old Asian female was referred to us for the diagnosis and treatment of an anterior mediastinal tumor. The tumor was $80 \mathrm{~mm}$ in the largest diameter and was located on the pericardium. No invasion was evident. She underwent resection of the tumor via video-assisted thoracoscopic resection. The tumor was totally encapsulated, and its pedicle was on the pericardium. The resected specimen was very rigid, making it difficult to remove from the intercostal space. Histologically, the tumor was composed of a paucicellular dense collagenous tissue. Mitosis was rarely observed, and cellular atypia was not evident, suggesting that the tumor was benign. We diagnosed the tumor as a desmoplastic fibroblastoma by morphology and immunohistochemistry.
\end{abstract}

Conclusions: Desmoplastic fibroblastoma of the mediastinum is an extremely rare disease. Preoperative diagnosis is difficult. Early surgical resection is suitable for diagnosis and treatment planning.

Keywords: Desmoplastic fibroblastoma, Collagenous fibroma, Mediastinal tumor, Video-assisted thoracoscopic surgery, Case report

\section{Background}

Desmoplastic fibroblastomas (also known as collagenous fibromas) are benign, collagen-rich soft-tissue tumors. This tumor occurs most frequently in middle-aged adult males. It mainly develops in the limb, neck, and trunk. Histologically, this tumor is characterized by hypocellularity and dense wavy bands of collagenous fibers. This tumor usually appears as a solitary encapsulated mass and grows slowly. Here, we report a rare case of desmoplastic fibroblastoma that arose from the pericardium.

*Correspondence: taihato@saitama-med.ac.jp

1 Department of General Thoracic Surgery, Saitama Medical Center, Saitama Medical University, 1981 Kamoda, Kawagoe, Saitama, Japan Full list of author information is available at the end of the article
Preoperative diagnosis of this tumor was quite difficult. In our case, the tumor size almost doubled within a year, but mitosis was seldomly seen histologically, suggesting that collagen production caused the enlargement of the tumor. To our knowledge, this is the first case of desmoplastic fibroblastoma developed from the pericardium in the literature.

\section{Case presentation}

A 32-year-old Asian female visited us for examination of an abnormality on her chest X-ray. There was a welldefined mass lesion around the apex of the heart. The mass had developed and grown within 1 year (Fig. 1A, B). The tumor size enlarged from 34 to $64 \mathrm{~mm}$ in the original author(s) and the source, provide a link to the Creative Commons licence, and indicate if changes were made. The images or other third party material in this article are included in the article's Creative Commons licence, unless indicated otherwise in a credit line to the material. If material is not included in the article's Creative Commons licence and your intended use is not permitted by statutory regulation or exceeds the permitted use, you will need to obtain permission directly from the copyright holder. To view a copy of this licence, visit http://creativecommons.org/licenses/by/4.0/. The Creative Commons Public Domain Dedication waiver (http://creativeco mmons.org/publicdomain/zero/1.0/) applies to the data made available in this article, unless otherwise stated in a credit line to the data. 


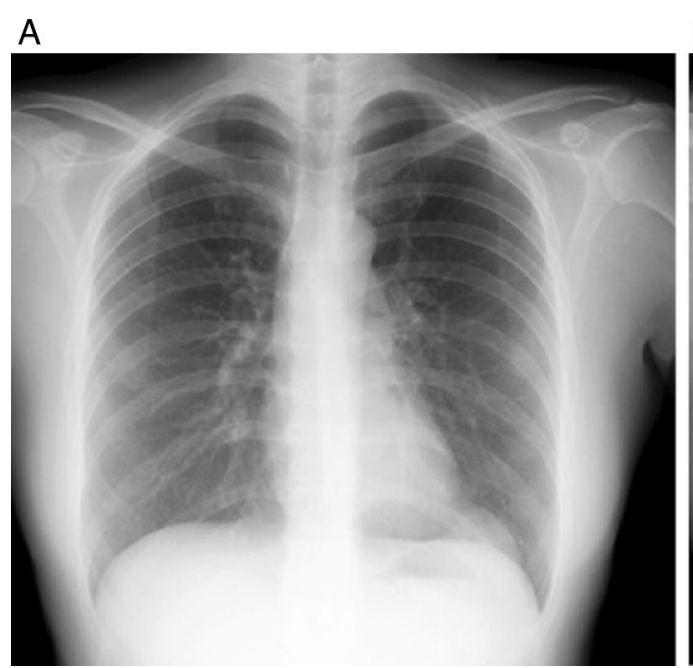

B

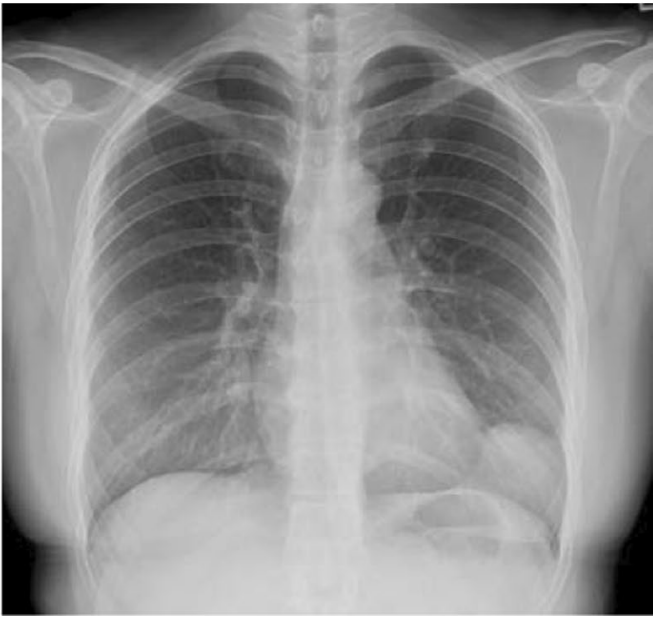

Fig. 1 Chest X-ray taken in A 2018 and B 2019. The tumor size enlarged from 34 to $64 \mathrm{~mm}$ in the largest diameter

largest diameter by chest X-ray. The patient was asymptomatic, had never smoked, and had a history of hyperthyroidism treated with thiamazole. However, she was medication-free on admission to our hospital. She had no history of pregnancy and no history of childbirth. There was no remarkable family history of illness, including cancer. She is a desk worker with no history of exposure to certain chemicals or asbestos. Her vital signs, physical examination, and neurological examination on admission were unremarkable. Her laboratory finding was within the standard limit on blood cell counts, liver and renal functions, urinalysis, and other serology. Chest computed tomography (CT) revealed a pear-shaped mass lesion measuring $80 \mathrm{~mm}$ in the largest diameter that had developed between the pericardium and the left lung (Fig. 2). The lesion was monotonous and had a computed tomography value between 23 and $32 \mathrm{HU}$. It was growing expansively and did not seem to invade the adjacent organs. The lesion showed a low signal on T1-weighted magnetic resonance imaging (MRI) and a low and heterogeneous signal on T2-weighted fat-saturation imaging (Fig. 3A, B).

The preoperative diagnosis was a benign anterior mediastinal tumor or a thymoma. Video-assisted thoracoscopic resection of the tumor was performed under general anesthesia. The patient was placed in the right lateral position. An $11.5 \mathrm{~mm}$ port was placed in the seventh intercostal space at the lower end of the scapula. Two $5 \mathrm{~mm}$ ports were set in the fifth and ninth intercostal spaces on the anterior and posterior axial lines. The tumor was located on the pericardium, slightly anterior to the phrenic nerve (Fig. 4A). It was an encapsulated mass and did not appear to invade the lung or

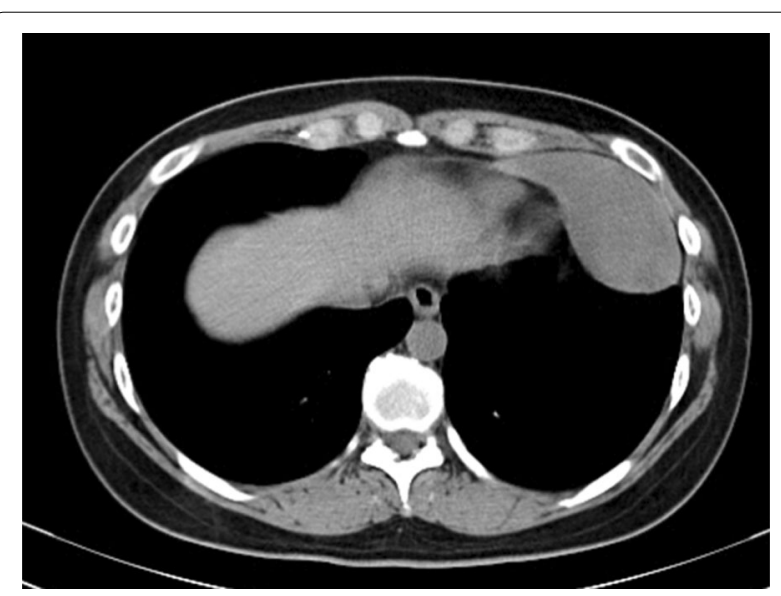

Fig. 2 Chest computed tomography image of the tumor. The tumor was located on the pericardium and did not seem to invade the adjacent organs. The tumor had a pedicle on the pericardium

diaphragm. We exfoliated the tumor and fat tissues from the pericardium. The tumor had a pedicle on the pericardium, suggesting its origin (Fig. 4B). After the tumor was resected, we placed it in the specimen bag and attempted to remove it through the largest port. However, the lesion was very rigid, so we could not remove it. We had to enlarge the wound to $35 \mathrm{~mm}$. Her postoperative course was uneventful. She was followed up with computed tomography for 2 years with no evidence of recurrence.

The resected tumor was completely encapsulated. There was no invasion to the surrounding pericardial fat or thymus. Macroscopically, the cut surface of the tumor showed a dense mesh network of collagen fibers (Fig. 5A). Hematoxylin-eosin staining showed that the 


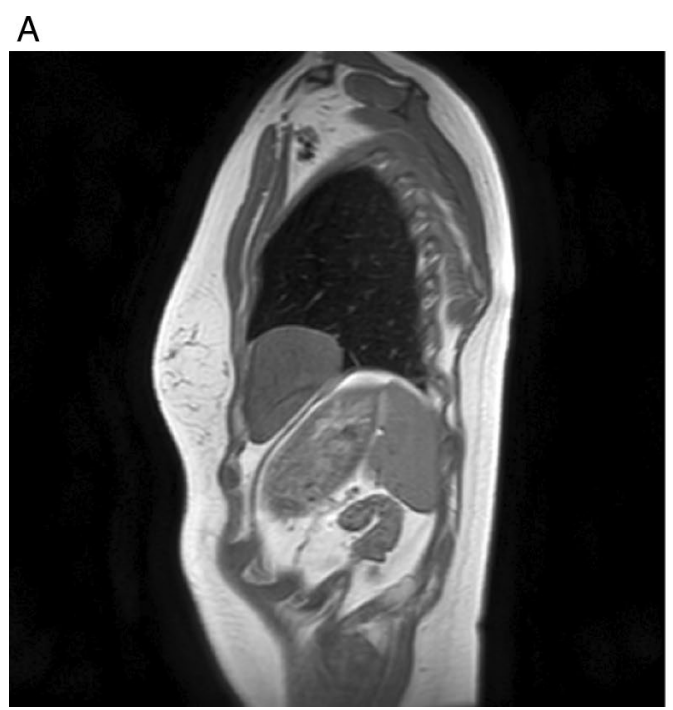

\section{B}

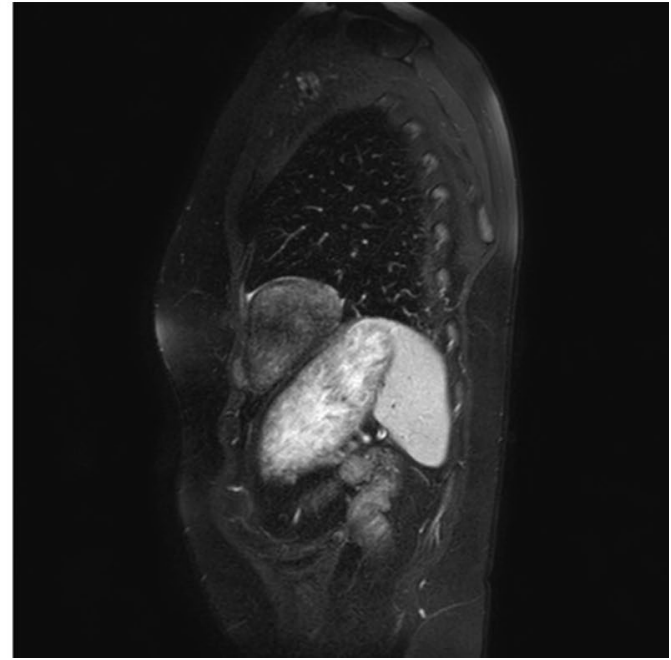

Fig. 3 Magnetic resonance images of the tumor. A T1-weighted image. B T2-weighted fat-saturation image. There was no fat intensity detected inside the tumor
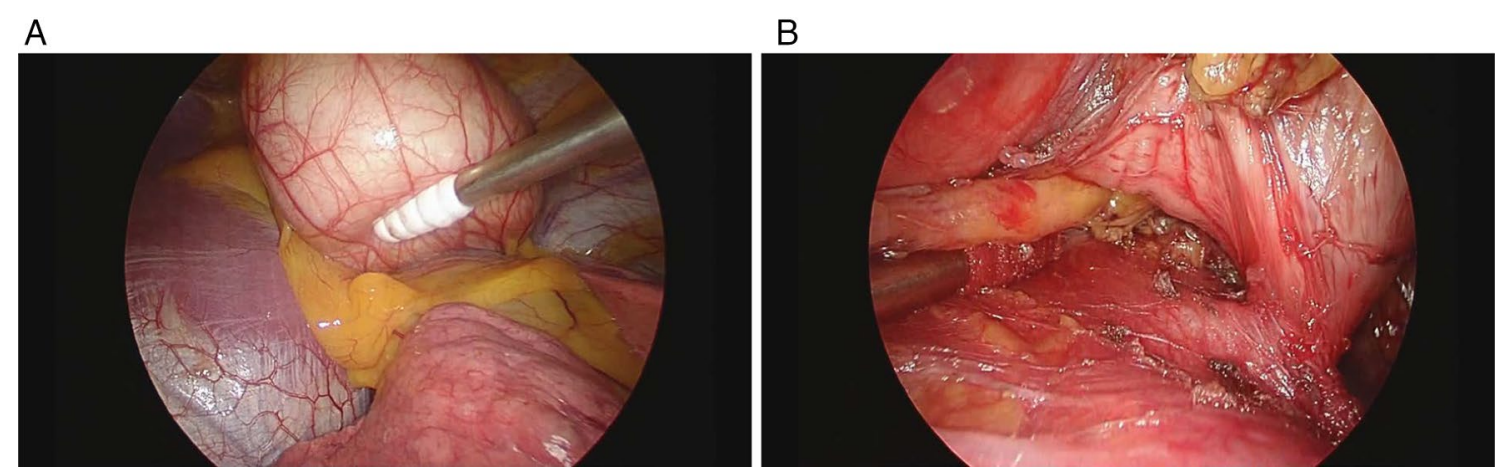

Fig. 4 Intraoperative findings. A The tumor was located on the pericardium slightly anterior to the phrenic nerve. B The tumor was pushed aside with a cotton stick. The pedicle of the tumor was connected to the pericardium

paucicellular tumor was composed of vaguely arranged bundles of wavy collagen fibers (Fig. 5B). The pedicle of the tumor was composed of longitudinally arranged fibrous bundles connected to the pericardium, suggesting its origin (Fig. 5C). The cellularity was sparse. The tumor cells did not seem to be atypical. Some nonspecific lymphocyte (or mononuclear cell) infiltration could be seen around the tumor vasculature with different intensities. Immunohistochemical analysis showed a positive reaction for alpha-smooth muscle actin ( $\alpha$ SMA), desmin, and CD34. Integrase interactor 1 (INI1) expression was intact. Staining for cytokeratin (AE1/AE3), epithelial membrane antigen (EMA), $\beta$-catenin, S100 protein, D2-40, MDM2, and STAT6 was negative. There was no infiltration of IgG4-positive plasma cells. These results suggested fibroblastic or myofibroblastic differentiation. The Ki-67 labeling index was less than 5\%. Anaplastic leukemia kinase (ALK) staining was negative on immunohistochemistry. Fluorescent in situ hybridization indicated no breakage of the ALK gene. Finally, the tumor was diagnosed as desmoplastic fibroblastoma.

\section{Discussion}

We report a rare case of desmoplastic fibroblastoma originating from the pericardium. To the best of our knowledge, our study is the first report of a tumor developed in the anterior mediastinum.

Desmoplastic fibroblastoma (also known as collagenous fibroma) is a benign, slow-growing soft-tissue tumor. Evans et al. reported the first case in 1995 [1]. This tumor 

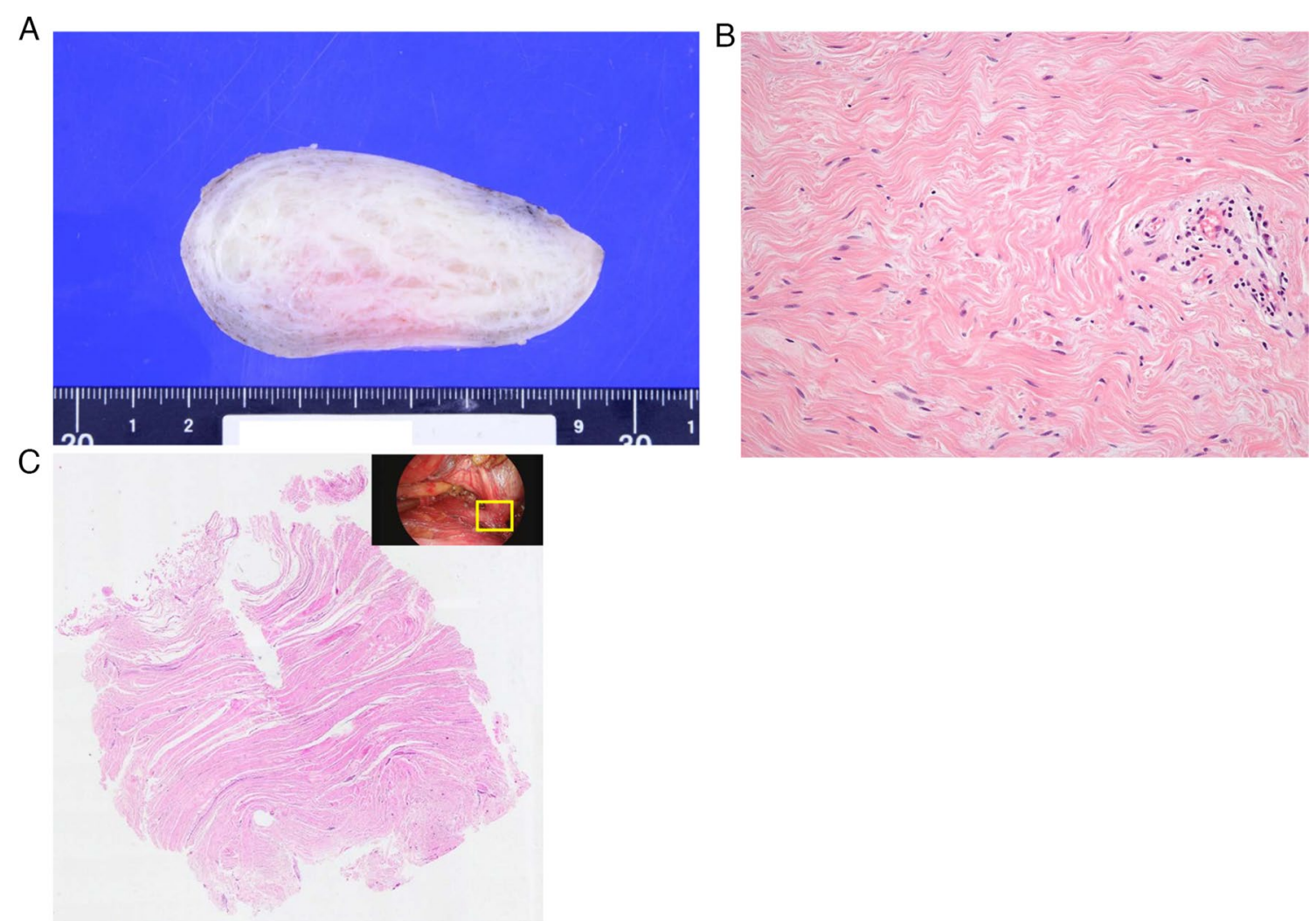

Fig. 5 Macroscopic and microscopic findings of the tumor. A Gross appearance of the tumor. The cut surface of the tumor showed a dense mesh network of collagen fibers. B Hematoxylin-eosin staining showed that the paucicellular tumor was composed of vaguely arranged bundles of wavy collagenous fibers. CThe pedicle of the tumor was composed of longitudinally arranged fibrous bundles connected to the pericardium, suggesting its origin

occurs mainly in middle-aged or older men [2]. Most of these tumors arise in subcutaneous tissues, the fascia, and skeletal muscles. Common sites of origin include the limbs, neck, and trunk [2, 3]. However, rarer sites of origin have also been reported, including the palate, parotid glands, and thyroid glands [4-6]. One case involving a chest wall origin was reported, but a pericardial origin is quite rare [7].

The preoperative diagnosis was difficult. Computed tomography showed a uniform tumor connected to the pericardium. The computed tomography value of the tumor and the MRI findings excluded the probability of cystic disease. Imaging differential diagnosis included diverse kinds of soft-tissue tumors and thymic epithelial tumors. However, the pear shape of the tumor is not typical of thymoma. Both CT and MRI showed no fat component inside the tumor, so lipoma and liposarcoma were ruled out. Due to the rarity of soft-tissue tumors of the mediastinum, further diagnosis by imaging alone was difficult.

Interestingly, the tumor grew almost double in size within a year. However, mitosis was seldom seen microscopically. This would suggest that the tumor produced abundant fibrous tissues that mimicked tumor growth. Because the collagenous fibers were quite dense, we could not shape or compress the tumor to extract it through the intercostal space.

The histologic differential diagnosis included desmoidtype fibromatosis, solitary fibrous tumor, sclerosing rhabdomyosarcoma, and inflammatory myofibroblastic tumor. The absence of $\beta$-catenin immunostaining and the morphology did not match desmoid-type fibromatosis. Monotonous histology, lack of the pericytomatous pattern of the vasculature, and negativity of STAT6 staining excluded the possibility of solitary fibrous tumor. The lack of atypia and mitosis did not match the features of rhabdomyosarcoma. Neither ALK staining on immunohistochemistry nor breakage of the ALK gene on fluorescent in situ hybridization was detected. Therefore, the probability of an inflammatory myofibroblastic tumor was also low. Finally, the tumor was diagnosed as desmoplastic fibroblastoma. It has been reported that immunohistochemical studies are of little help in making a diagnosis of desmoplastic fibroblastoma because 
of the lack of tumor-specific markers [8]. Nevertheless, immunohistochemical examinations are useful for exclusionary diagnosis. The limitation of this case report is the unavailability of cytogenetic analysis. Cytogenetic analysis describing a chromosomal rearrangement in $11 \mathrm{q} 12$ and translocation $(2 ; 11)$ has been reported in the diagnosis of desmoplastic fibroblastoma [3]. However, an in situ hybridization probe was not available for this case. Instead, we attempted whole-genome sequencing for this tumor. Unfortunately, it was impossible because the quality and amount of DNA from the formalin-fixed paraffinembedded samples was insufficient. DNA sampling was impossible due to the desmoplastic nature and scant cellularity of this tumor.

\section{Conclusions}

We report the first case of desmoplastic fibroblastoma arising from the pericardium. A preoperative diagnosis of this kind of tumor is almost impossible. The tumor grows quickly, but little mitosis is seen in histology. Surgical resection is suitable for the diagnosis and cure of this benign disease.

\section{Acknowledgements \\ Not applicable.}

\section{Authors' contributions}

TH and $\mathrm{MN}$ designed the report. HK, MY, AS, YI, KA, FH, and TH collected the patient's clinical information. TH, GM, JK, TY, MK, and MN wrote the paper. JK, JT, TF, and TY performed the pathologic analyses. All authors read and approved the final manuscript.

\section{Funding}

The authors declare no financial support.

\section{Availability of data and materials}

All data used and analyzed during the current study are available from the corresponding author on reasonable request.

\section{Declarations}

Ethics approval and consent to participate

The ethics committee of Saitama Medical University approved this study (reference no. 2349). The patient signed a consent form for her medical information to be published.

\section{Consent for publication}

Written informed consent was obtained from the patient for publication of this case report and any accompanying images. A copy of the written consent is available for review by the Editor-in-Chief of this journal.

\section{Competing interests}

The authors declare that they have no competing interests.

\section{Author details}

${ }^{1}$ Department of General Thoracic Surgery, Saitama Medical Center, Saitama Medical University, 1981 Kamoda, Kawagoe, Saitama, Japan. ${ }^{2}$ Department of Pathology, Saitama Medical Center, Saitama Medical University, 1981 Kamoda, Kawagoe, Saitama, Japan. ${ }^{3}$ Department of Pathology, Saitama International Center, Saitama Medical University, Hidaka, Saitama, Japan. ${ }^{4}$ Department of Pathology, Nikko Medical Center, Dokkyo Medical University, Nikko, Tochigi, Japan.

Received: 11 May 2021 Accepted: 14 July 2021

Published online: 18 October 2021

\section{References}

1. Evans HL. Desmoplastic fibroblastoma. A report of seven cases. Am J Surg Pathol. 1995;19(9):1077-81.

2. Miettinen M, Fetsch JF. Collagenous fibroma (desmoplastic fibroblastoma): a clinicopathologic analysis of 63 cases of a distinctive soft tissue lesion with stellate-shaped fibroblasts. Hum Pathol. 1998;29(7):676-82.

3. Sciot R, Samson I, van den Berghe H, Van Damme B, Dal Cin P. Collagenous fibroma (desmoplastic fibroblastoma): genetic link with fibroma of tendon sheath? Mod Pathol. 1999;12(6):565-8.

4. Mesquita RA, Okuda E, Jorge WA, de Araujo VC. Collagenous fibroma (desmoplastic fibroblastoma) of the palate: a case report. Oral Surg Oral Med Oral Pathol Oral Radiol Endodontol. 2001;91(1):80-4.

5. Ide F, Shimoyama T, Horie N, Tanaka H. Collagenous fibroma (desmoplastic fibroblastoma) presenting as a parotid mass. J Oral Pathol Med. 1999;28(10):465-8.

6. Wilson C, Summerall J, Lubin J, Mesko TW. Collagenous fibroma (desmoplastic fibroblastoma): a unique presentation as a goiter in an 88-year-old man. Ann Diagn Pathol. 2000;4(3):165-9.

7. Kawaguchi Y, Fujita T, Hanaoka J. Invasive desmoplastic fibroblastoma in the chest wall. Ann Thorac Surg. 2015;99(4):e85-86.

8. Nielsen GP, O'Connell JX, Wehrli BM, Rosenberg AE. Collagen-rich tumors of soft tissues: an overview. Adv Anat Pathol. 2003;10(4):179-99.

\section{Publisher's Note}

Springer Nature remains neutral with regard to jurisdictional claims in published maps and institutional affiliations.

Ready to submit your research? Choose BMC and benefit from:

- fast, convenient online submission

- thorough peer review by experienced researchers in your field

- rapid publication on acceptance

- support for research data, including large and complex data types

- gold Open Access which fosters wider collaboration and increased citations

- maximum visibility for your research: over 100M website views per year

At BMC, research is always in progress.

Learn more biomedcentral.com/submissions 